\title{
An Assessment of Technology Forecasting: Revisiting Earlier Analyses on Dye-Sensitized Solar Cells (DSSCs)
}

\author{
Ying Huang ${ }^{1}$, Alan L. Porter ${ }^{2,3}$, Yi Zhang ${ }^{4}$, Xiangpeng Lian ${ }^{5}$, Ying Guo ${ }^{5, *}$ \\ ${ }^{1}$ Department of Public Administration, Hunan University, Changsha 410082, China \\ ${ }^{2}$ School of Public Policy, Georgia Institute of Technology, Atlanta, GA 30332, USA \\ ${ }^{3}$ Search Technology, Inc., Norcross, GA 30092, USA \\ ${ }^{4}$ Faculty of Engineering and Information Technology, University of Technology, Sydney, NSW 2007, \\ Australia \\ ${ }^{5}$ School of Management and Economics, Beijing Institute of Technology, Beijing 100081, China \\ *Corresponding author e-mail: guoying_bit@163.com (Ying Guo)
}

\begin{abstract}
The increasingly uncertain dynamics of technological change pose special challenges to traditional technology forecasting tools, which facilitates future-oriented technology analysis (FTA) tools to support the policy processes in the fields of science, technology \& innovation (ST\&I) and the management of technology (MOT), rather than merely forecasting incremental advances. Through a series of technological forecasting studies analyzing the R\&D patterns and trends in Dye-sensitized solar cell technology over the past several years, we have come to realize that validating previous forecasts is useful for improving STI policy processes. Dye-sensitized solar cells are a promising third-generation photovoltaic technology that can add functionality and lower costs to enhance the value proposition of solar power generation in the early years of the 21 st century. Yet, rarely do we revisit forecasts or projections to ascertain how well they fared. Moreover, few studies pay much attention to assessing FTA techniques. In this paper, we compare recent technology activities with previous forecasts to reveal the influencing factors that led to differences between past predictions and actual performance. Beyond our main aim of checking accuracy, in this paper, we also wish to gain some sense of how valid those studies were and whether they proved useful to others in some ways.
\end{abstract}

Keywords: Technology Forecasting; Technology Foresight; Technology Emergence; Research Evaluation; Dye-Sensitized Solar Cells (DSSCs) 


\section{Highlights:}

1. This paper presents a framework for revisiting technology forecasting activities from the perspectives of technology life cycle, basic technology profiling and enhanced technology detection;

2. It provides an empirical assessment to validate prior forecasts rather than a detailed process to conduct technology forecasting or technology foresight;

3. It attempts to compare recent technology activities with previous forecasts to reveal the influencing factors that led to differences between past predictions and actual performance, which should provide insights for future-oriented technology analyses;

4. The focus of the analysis extends beyond identifying hot technical topics to include the leading actors, prominent organizations, and countries most heavily engaged in the field;

5. Emphasis is placed on the leading actors in the current stage, as well as the emerging actors who have the potential to play a prominent role in future activities rather than. 


\section{INTRODUCTION}

Newly emerging science and technologies (NESTs) are expected to bring both considerable wealth and numerous opportunities and challenges to innovation activities. As NESTs are radically novel, relatively fast-growing, and characterized by a certain degree of coherence, these forms of technologies tend to be more dependent on intermittent advances [1]. The anticipated (disruptive) impacts on markets and on society are more difficult to foresee than a steady and incremental innovation process, and the highly uncertain dynamics of NESTs pose special challenges to traditional technology forecasting tools.

In an environment facing the complexity of a growing number of NESTs, decision makers need to be able to capture current and strategic intelligence on a range of technologies and make forwardlooking assessments. Over the years, future-oriented technology analysis (FTA) tools have expanded beyond merely forecasting incremental advances. Most now purport to inform policy processes for those in the fields of science, technology \& innovation (ST\&I) and the management of technology (MOT). Hence, the ability to explore multiple potential innovation pathways [2] has become essential. Under such a background, the forecasting innovation pathways (FIP) framework including 4 stages and 10 steps has been constructed to analyze NESTs [3]. This framework incorporates "tech mining" [4] to ascertain developmental patterns, key participants, and potential application targets by analyzing large datasets drawn from ST\&I publication and patent databases, as well as contextual information resources (e.g., ABI Inform). As a multi-step process for analyzing ST\&I information resources, "tech mining" provides the empirical knowledge necessary to address, and then help to assess, mature or emerging fields of science and technology [5]. To complement the tech mining process, expert-based inputs, derived from interactive workshops, help to digest the empirical findings and lay out prospective developmental pathways.

The FIP approach can be treated as a bridge methodology that builds on a strong empirical base by incorporating informal expert opinions and aims to elucidate the forward pathways $R \& D$ activities might take in translating ideas into applications and is a valuable tool for exploring future development trajectories [6]. However, we need to accept that the activity of technology forecasting is focused on changes in technology; it is not deterministic. That is, technology forecasting does not seek to predict a single certain future [7]. Therefore, validating past results is an important step in adapting FTA-based methodologies to help analyze complex technologies with significant infrastructure in place.

Photovoltaics is one emerging technology that has gathered much attention over the past several years due to its potential for decreasing costs and its broad applicability. Within this innovative technology, a promising third-generation form of photovoltaics - Dye-sensitized solar cells (DSSCs) - is gathering momentum as an economically and environmentally-viable alternative to traditional devices [8]. DSSCs technology has witnessed increasing R\&D activity since 1991 and is anticipated to continue with rapid commercialization in the future [9]. The program in Science, Technology, and Innovation Policy (STIP) at the Georgia Institute of Technology is actively involved in characterizing the nanotechnology industry and its dynamics through data mining techniques, such as bibliographic database analysis (yielding bibliometric data) and patent database analysis (yielding intellectual 
property data), as well as through text-mining, interviews, and other research methods [10]. Additionally, since 2008, the Innovation Co-Lab (Georgia Institute of Technology STIP, Manchester institute of innovation research, University of Manchester, and School of Management and Economics, Beijing Institute of Technology) has been analyzing DSSCs R\&D activity patterns and trends through a series of studies that include: (1) research profiles and technology opportunity analysis [11-15]; (2) collaboration networks and patterns [16, 17]; and (3) the FIP approach, which includes technology delivery systems [18], estimating innovation risks [19], and technology roadmapping of evolutionary pathways [20-24].

With this objective in mind, in this paper, we revisit our earlier assessments and projections with an updated DSSCs data collection to assess the accuracy of past forecasts and rethink how to improve the reliability of technology forecasting. FTA purports to inform MOT and ST\&I policy processes. Yet, rarely do we revisit forecasts or projections to ascertain how well they fared, nor does previous research pay much attention to assessing the efficacy of the forecasting method used. One of our aims is to check accuracy, to gain some sense of how valid those studies were and whether they proved useful to others in some ways. Additionally, we want to assess the degree to which these analyses did or did not make good use of the information available at the time. Moreover, we seek indications of which information is key, and how FTA processes can better use that information.

The remainder of this paper consists of five sections. Following this general introduction, the related reviews on technology forecasting are provided in the "Related Literature" section. The "Framework and Data" section describes the framework we used for assessing the technology forecasts along with the data we used in the analysis. The "Results and Findings" section explores how the stage of a technology's development was identified, the focal countries and regions, the prominent technological actors, the distribution of sub-fields, and the past and future potential of various sub-technologies through a comparative analysis. The foci of this section is on comparing recent technology activities with previous forecasts to reveal the influencing factors that led to differences between past predictions and actual performance. The "Conclusions and Discussion" section reviews the results in terms of the proposed research questions and identifies the limitations and promising opportunities found in this research for the future.

\section{RELATED LiteratURE}

Technology forecasting is treated as a way to help enterprises to formulate technology strategies and policies by identifying core and emerging technologies [25]. Much research has been undertaken in the study of technology forecasting, and this section provides a review of the relevant technology forecasting methods in the literature.

\subsection{Qualitative method: Represented by Delphi technology forecasting approach}

The Delphi method is viewed as an efficient procedure for obtaining a reliable consensus opinion from a group of experts through a series of intensive questionnaires interspersed with controlled opinion feedback [26]. It is a qualitative decision-making method and the accuracy of the decisions are mainly determined by the knowledge level of the experts. Delphi is well suited to technology 
forecasting, particularly because of its ability to produce long-range and large-scale forecasts, and, with this method, core technologies can be identified and forecast relatively easily [27].

However, conventional Delphi methodologies have some drawbacks and, therefore, several alternatives have been developed to overcome these shortcomings. For example, Yun and Soung [28] developed a technology forecasting approach based on a semi-Markov model, which primarily focuses on capturing the information Delphi surveys skip. To enhance Delphi's analytical power, Hussler, Muller, and Ronde [29] proposed increasing diversity within the panel groups. Bloem da Silveira et al. [30] combined other techniques, including morphological analysis, decision matrices, interviews, and prioritization analysis, with the Delphi method to construct technology roadmaps. More recently, a real-time spatial Delphi technique was introduced to provide an innovative way of eliciting expert opinions using a simple and intuitive platform [31]. Wakefield and Watson's [32] reappraisal of Delphi 2.0 perhaps provides one of the best showcases for how a qualitative approach such as Delphi can be quite useful for exploring complex issues in a given domain by gathering selected experts on a particular topic.

\subsection{Quantitative method: Represented by Science \& Technology(S\&T) data analysis}

Methods based on expert opinions, such as Delphi, provide a subjective consideration of contextual changes through the implicit mental models each expert has internalized about the nature and likelihood of change. However, these methods tend to be both time-consuming and costly. To ameliorate these problems, many in the field of technology forecasting have turned to quantitative methods. When measuring a given technology directly is not possible, and a combination of tools can be used to help properly forecast technology trends [33]. Qualitative methods are useful when there is enough directly measurable data available [34], and science and technology documents, such as patents and academic papers, can provide this data to a certain degree [35].

Many interdisciplinary quantitative research methods have integrated bibliometric and patent analysis into technology forecasting. Overall, these approaches can be divided into four types. (1) Multi-indicator-based analyses, which introduce new metrics, like citations per patent, information about patent families, patent share, increases in the number of patents, and patent activity. For example, Choi, You, and Na's [36] analysis of next-generation mobile communication. (2) Textbased analysis including machine learning approaches, such as Kyebambe et al. [37], K-medoids clustering based on support vector clustering (KM-SVC) [38], and Latent Dirichlet allocation (LDA) for topic identification [39]. (3) Citation-based analysis, such as You et al.'s [40] forecast on the development trends of coherent light generator technology. (4) Hybrid approaches, such as enhancing the future-oriented performance of morphology analysis by combining it with conjoint analysis and citation analysis [41], applying co-classification analysis, or applying co-word analysis and main pathway analysis to reveal implicit or unknown patterns and discover significant clues about technology prospects [42]. 


\subsection{The combination of qualitative and quantitative analysis}

However, exclusively using either a qualitative or a quantitative approach may result in an incomplete view of technology forecasting [43]. Technology forecasting is sometimes viewed as an effort to collect information to posit about the future, the plausibility and limits of a technology, its internal consistency and conformity with models and data, or its consistency with expert judgment [44]. Expert knowledge might give a reasonable explanation of qualitative data, but combining expert knowledge with a qualitative appraisal can often improve forecast accuracy [45]. As some researchers point out, a quantitative approach, such as text mining, can reveal invisible information in patent data, and citation analysis may provide insights into the evolutionary pathways of a technology, while expert analysis can provide information that a layperson cannot glean [46].

This type of research has been conducted in several technology fields. For example, Chen, Chen, and Lee [47] combined bibliometric \& patent analysis with an expert survey to forecast the hydrogen energy and fuel cell technology. Zhang et al. [48] generated a global technology roadmap for electric vehicles using a hybrid bibliometric and qualitative methodology.

While much of the research above includes aspects of the design of technology forecasting approaches, some studies focus on the selection and comparisons of technology forecasting methods. Selecting a forecasting technique that considers the characteristics of the technology and the resources needed, such as cost and time, is essential. Intepe, Bozdag and Koc [49] proposed a solution for selecting a technological forecasting technique that includes seven selection criteria and twelve forecasting alternatives. Cheng, Chen and Chen [50] adopted a fuzzy AHP method to obtain selections for technology forecasting methods by professionals. Wilmot [51] published a brief critical analysis of how each of the existing methods for technological forecasting might influence the resulting conclusions about the nature of future developments.

From the above reviews, we can see many attempts have been conducted to analyze futureoriented activities or provide some insights to assist technology forecasting. However, research that revisits existing technology forecasts or its methods is relatively rare. By re-examining the analyses and conclusions produced with technology forecasting methods, adjustments and suggestions can be made to enhance their accuracy and reliability. To this end, this paper is an attempt to assess technology forecasting, especially science and technology data-based forecasting, through an empirical comparison of our past technological forecasts on DSSCs and a new forecast based on actual information that includes a further six years of evolution.

\section{FRAMEWORK AND DATA}

\subsection{Conceptual framework}

Technology forecasting focuses on changes in technology, such as its functional capacity, timing, or significance. Within the scope of technology forecasting, it is common to answer the following questions: (1) "What?" - what technologies or parts of technologies are likely to become the most promising sectors? (2) "When?" - when will those technological trends occur? (3) "Who?" - who will play a leading role in the R\&D and potential market for a given technology? (4) "Where?" 
- which countries or regions will make outstanding contributions to a technology's performance? (5) "How?" - how will a technology evolve from one stage to the next? (6) "Why?" - why will a technology evolve, and why will that change happen during a certain period of time?

Compared to technology forecasting itself, assessing a technological forecast or the method used to produce the forecast seeks to evaluate the activity in technological development from the perspective of data collection, technology life cycle analysis, compare basic technology profiling and validate enhanced technology detection. The time-lag between past and present provides a window for revisiting previous forecasts and analyses. An overview of the framework we used for assessing data-driven technology forecasting is shown in Fig 1.

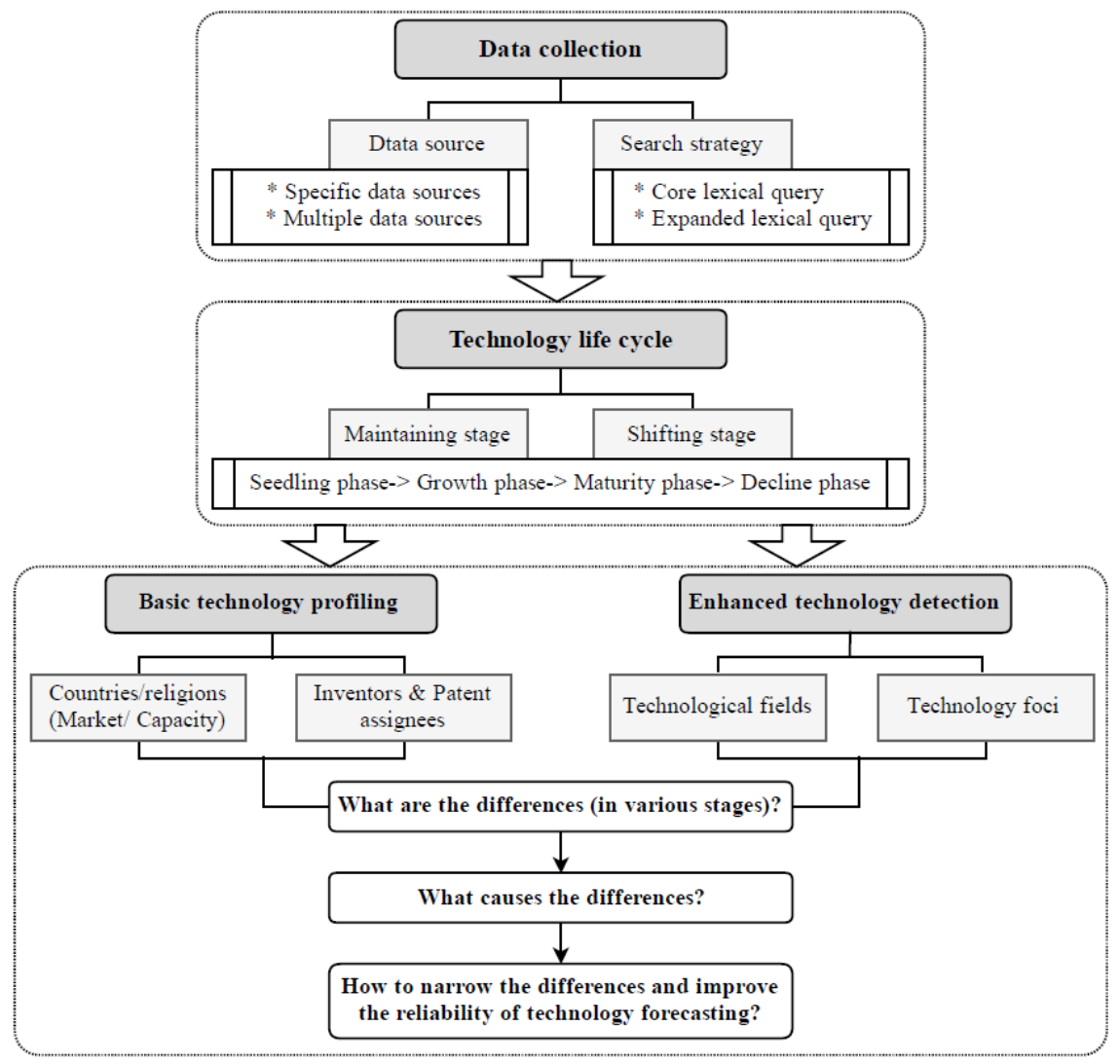

Fig. 1. A brief framework for assessing data-driven technology forecasting

Technology forecasting is likely to be more successful when diverse and effective sources of information are integrated to produce a convincing and holistic portrait of possible futures. As data sources and data quality become the foundational factors in most data-based technology forecasting system, so it is necessary to reconsider whether the search strategy is effective or acceptable in the new circumstance. Through experience, we have come to realize that searching for data in a domain with many commonly used terms can be particularly challenging. Hence, it is often easier to identify relevant research on a technical topic like DSSCs, than one involving a lot of broader computer science or managerial terminology, e.g., "Big Data" [52]. Selecting the right data source depends 
upon the specific technologies and topics being addressed. Further, the research question often drives the search for a corresponding data source. However, overall multiple sources of data are often beneficial for gathering a greater amount of information and for making more accurate forecasts. Patent data is usually the main source of information because it not only provides actual clues about the most important discoveries companies and inventors seek to protect, it also provides information about technologies that are nearing the market.

Technology forecasting methods can be classified as either extrapolative or normative - namely, by whether they extend present trends or look backward from a desired future to determine the developments that were needed to achieve those goals [7]. Given the main purpose of this assessment is to revisit previous analyses, using the same or a similar approach as the original study makes for a better comparison. However, one visible discrepancy that needs to been explained is that technology forecasting based on real activity must pay attention to both the functional capacity and relevant characteristic of the technology and also consider the structural interactions between the technology and the elements of its context. Technology often presents different development tracks; therefore, it is necessary to consider the technology life cycle (TLS) when creating a distinct R\&D strategy plan. The technology life cycle comprises a pattern of dynamic characteristics pertaining to technology, in which its innovative and economic outcomes change over time. Therefore, after obtaining the dataset of targeted technology, the first thing is to judge which stage the technology stays. In general, the whole life cycle can be divided into seeding phase, growth phase, maturity phase and decline phase. When we assess the technology stage, the main object is to analyze whether the cycle is maintaining as previously addressed or has shifted to next developmental phase.

Similar to technology forecasting, the analytical scope of assessing technology forecasts are centered on the key questions of "who, what, where, when, and how". In technology forecasting, one always cares more the leading country, the main institution, and the most prominent inventors, based on the assumption that they will perform just well going forward as they have in the past. However, the process of technological evolution is dynamic, so the role of a technological actor may change through various stages of development. Likewise, the best conceptual framework for representing an organization's beliefs, assumptions, and goals may also change. For such a basic profiling respective, the main research questions addressed here is what's role change associated with countries (priority country and family country) and regions, inventors and patent assignees among leading, emerging and declining status in various stages? Further, the most important purpose of technology forecasting is to outline the whole technological picture under the conditions at the time, so what the technological fields transform and what the technological foci evolve turn out to be essential and urgent. The further exploration on technological fields and technological foci are treated as the enhanced technology detection. Along with basic technology profiling, the primary task of those revisits is to answer the following three questions:

- First, What are the differences between past predictions and actual performance? These differences can be revealed by applying the same or a similar approach as the past forecast to analyze the current situation. Examining past performance to improve present performance can also be used to strengthen future approaches to technology forecasting. Therefore, examining the results of past forecasts can be beneficial for determining whether 
they were successful in limiting uncertainty [53]. Comparative processes that involve either single or hybrid methods can be used to conduct the analyses from multiple dimensions.

- Second, what cause these differences? This question seeks to identify to the factors that have influenced the results throughout the forecast phases. It is necessary to distinguish these factors are internal (such as data limitation) or external (such as misleading methods), contextual oversights (e.g. the growth of disruptive technology) or faulty assumptions (e.g. unconscious biases).

- Third, how to narrow the differences and improve the reliability of technology forecasting? The narrow range of probable futures presented in a forecast, augmented with continued updates, provides a sound basis for moving forward to implementation. Therefore assessing a technology forecast means tracking the differences, explaining the uncertainties, and bridging the gap by improving the technological parameters, surveying the environmental context, and converging diverse approaches based on complementary strengths.

This paper attempts to identify the strengths and weaknesses of our previous DSSCs analyses in terms of data characteristics, projection accuracy, and the stability of the actors and networks. The results should provide insights for improving current FTA methodologies and validating other FTA analyses. For this analysis, we mainly selected 2010 as the boundary for comparison between our previous studies and this study.

\subsection{Data retrieval}

Obviously, in a data-driven analysis, the quality of the data is critical. Accurate data-based forecasting of emerging technologies is still problematic mainly due to the absence of effective data, which affected by the selection of data source and the strategy of data retrieval. In the past few years, our team has worked with multiple search strategies. Among them, the search strategy for DSSCs has been tuned several times. The previous search strategy and the current one are arrayed in Table 1. After repeated verification, the search query we favor is: $\mathrm{ABD}=\left(\left(\mathrm{Dye}^{*}\right.\right.$ or Pigment*) and (Sensiti*) and (Solar* or Photovoltaic*) and (Cell* or Batter*)).

Table 1. The past and current DSSCs search strategies

\begin{tabular}{|c|c|}
\hline Type & Search strategy \\
\hline Past & 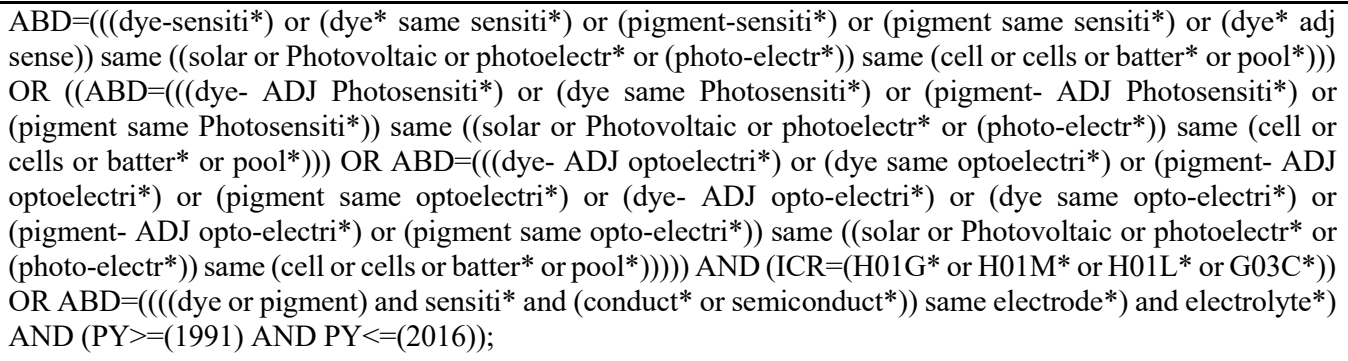 \\
\hline Current & $\mathrm{ABD}=(($ Dye* or Pigment*) and $($ Sensiti*) and (Solar* or Photovoltaic*) and (Cell* or Batter*)) \\
\hline
\end{tabular}

Note: ABD denotes Abstract; ICR represents the International Patent Classification (IPC); PY denotes the publication year. 
In this paper, we update DSSCs searches from Derwent Innovation, a platform that provides a comprehensive patent solution covering more than 50 patent-issuing authorities. The comparative search results are shown in Fig. 2. We can see that current retrieval results cover most of the previous records and doesn't present an obvious difference compared with previous one. After manual reading the abstract of disparate 333 records $(187+146)$, we conclude that the newly added 187 records are mostly indeed belong to the scope of DSSCs (e.g. Manufacturing method of dye sensitive solar panel for display substrate of cellular phone, involves coating nano-sized crystalline titania powder on glass substrate, and plasticizing titanium film at specific temperature (Patent NO. KR2013050322)) and excluded 146 records are mostly outside the category of DSSCs (e.g. Electrochromic device, useful e.g. as rearview mirror, comprises first substrate having transparent conductor coated surface, second substrate having second conductor coated surface, and electrochromic medium disposed between substrates (Patent NO. US2004257633)). Above all, current search terms is much easier to understand for such a specific research area. Therefore, we tend to believe our current search terms are effective to conduct this research. Ultimately, we retrieved on September 10. 2017, resulting 8155 patent records published between 1991 and 2016.

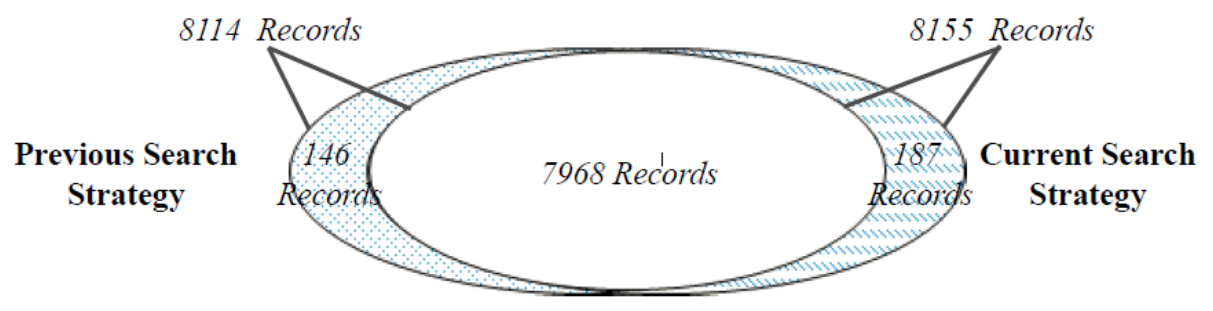

Fig. 2. The comparative search results in literature and patents

\section{RESULTS AND FINDINGS}

\subsection{Refine technology life cycle}

Understanding the long-term patterns of innovation is the most fundamental aspect of technology forecasting and public policy planning. Technology forecasting calls for a dynamic perspective, so identifying the current stage in a technology's life cycle (TLC) is essential for estimating its future development trends [54]. Various growth curves have been used to represent TLCs, such as logistic, Gompertz, Weibull Curves and the generalized function (aka Richards' curve). Overall, the analytical results from past literature demonstrate that models based on logistic growth curves (S-curves) are a highly effective means of quantifying technology forecasting with cumulative publications or patent activity [55].

Logistic analysis involves the decomposition of growth and diffusion patterns into S-shaped logistic components. Most previous studies tend to apply a logistic model without further consideration. However, the technological development trends can sometimes resemble a succession of several curves, and the overall logistic behavior of a technology tends to be hard to discern and analyze if the selection of growth form is inappropriate. Here, we introduce the online analytics toolLoglet Lab (http://www.logletlab.com ) to assist our analyses. The parameter statistics for the period 
1991-2010 and 1991-2016 are shown in Table 2. In both stages, the results for most parameters indicate that a 1-wave model performed better than a 2 -wave model. Thus, we chose the 1-wave logistic model.

Table 2. The parameter statistics results of the logistic model for 1991-2010 and 1991-2016

\begin{tabular}{|c|c|c|c|c|c|c|c|c|}
\hline \multirow{3}{*}{ Parameter } & \multicolumn{4}{|c|}{$1991-2010$} & \multicolumn{4}{|c|}{$1991-2016$} \\
\hline & \multirow[t]{2}{*}{ 1-Wave } & \multicolumn{3}{|c|}{ 2-Wave } & \multirow[t]{2}{*}{ 1-Wave } & \multicolumn{3}{|c|}{ 2-Wave } \\
\hline & & Phase 1 & Phase 2 & Whole fit & & Phase 1 & Phase 2 & Whole fit \\
\hline SSE & 26489 & 597313 & 100600 & 597313 & 123916 & 2606835 & 401407 & 2697728 \\
\hline RMS & 47 & 173 & 120 & 173 & 85.4 & 361 & 200 & 322 \\
\hline MAD & 43.7 & 131 & 98.8 & 131 & 70 & 278 & 171 & 234 \\
\hline MAPE & 0.115 & 0.535 & 0.836 & 0.518 & 0.0637 & 0.473 & 0.646 & 0.443 \\
\hline $\mathrm{SE}$ & 54.3 & 187 & 159 & 207 & 94.1 & 392 & 239 & 367 \\
\hline $\ln [\mathrm{MLE}]$ & -63.2 & -132 & -43.4 & -132 & -99.7 & -148 & -67.2 & -188 \\
\hline $\mathrm{AICc}$ & 135 & 272 & 101 & 283 & 207 & 304 & 144 & 393 \\
\hline R2 & 0.994 & 0.952 & 0.967 & & 0.997 & 0.962 & 0.996 & \\
\hline
\end{tabular}

Note: RMS - root mean square; MAD - mean absolute deviation; SSL - sum of log of squares; SE - standard error; SSE sum of square errors; AICc - Akaike information criterion for model selection; MLE - maximum likelihood estimation.

Figure 3 plots the composite fit by showing trends based on cumulative activity. The patents drawn from the DWPI database in Derwent Innovation exhibited a remarkable increase after 2000. Both fits predict sustained growth after 2010, but the fit for 1991-2016 predicts a descending trend after 2012. Even though the time lag is a common factor that cannot be ignored, the trend for cumulative patents represents an inflection point for slower growth.

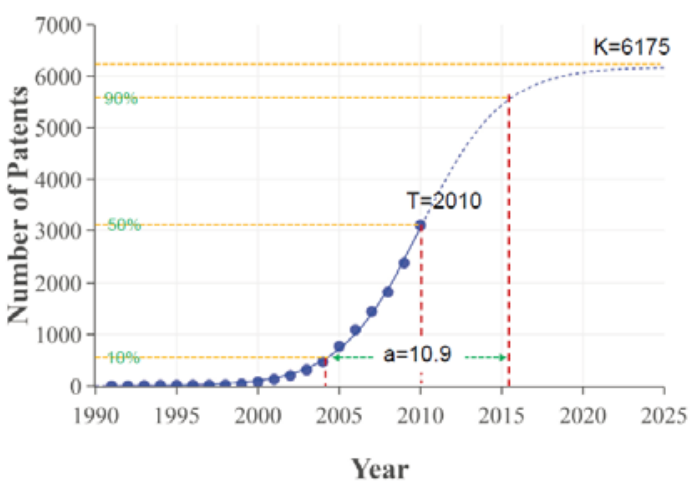

(a) 1991-2010

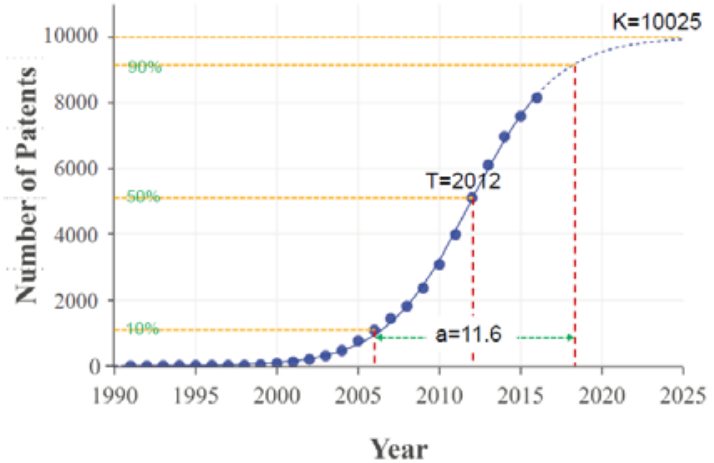

(b) 1991-2016

Fig. 3. The composite fit of the DSSCs patents for 1991-2010 and 1991-2016.

Note: ' $\mathrm{K}$ ' means the "carrying capacity" of the model (the saturation value of the S-shaped logistic); ' $a$ ' is the "growth rate", which is related to the time for the logistic curve to rise from $10 \%$ of $\mathrm{k}$ to $90 \%$ of ' $\mathrm{k}$ '; ' $\mathrm{T}$ ' is the midpoint of the logistic curve (the time when $\mathrm{p}(\mathrm{t})$ reaches $50 \%$ of ' $\mathrm{k}$ '.

To further judge the DSSCs technology life cycle, we also model growth using S-shaped curves. The parameterization of the logistic function, which is useful for time-series datasets, is also added to Fig.3. What is surprising is that the midpoints for the two logistic curves and the carrying capacities 
are different. In general, a technology's life cycle can always be divided into four stages: the emerging stage, the growth stage, the maturity stage, and the saturation stage. The midpoint is treated as the sign where a technology enters the maturation stage. Based on this assumption, we can identify that DSSCs are currently entering the maturation stage, where management decisions tend to be about evolutionary improvements in features, quality, and costs. Moreover, DSSCs are likely to enter the saturation stage in around 2018, when other new and emerging solar cell technologies might be garnering more attention. Such a conclusion could not be drawn based on the data up to 2010. Further, if the technology forecast was made in 2010, the results would probably show that DSSC technology would reach maturity in 2010, rather than 2012. However, it is important to note that this problematic judgment is likely due to inadequate data rather than forecasting method itself. Therefore, with frequent forecasts, it is necessary to limit the time horizon to an appropriate range.

\subsection{Compare basic technology profiling}

\subsubsection{The changes in technical powers and technological markets}

At the country level, the priority country and the patent family country are the main dimensions of technology forecasting activities. The first priority country generally serves as a proxy for the geographical origin of the patents. Considering the high cost of patent applications and maintenance, patents pursued in multiple countries tend to have a higher perceived commercial potential. In general, more patents applications in a certain country or region reflect a higher perception of a commercial market for developing this technology. So, patent family analysis is used to understand the layout of a country's potential markets.

To better figure out what is gap between what we indicated before and current real situation, we select the leading 5 countries/ regions both in priority country and family country and plot the related value in different stages. The arrows show the value changed from certain stages to next stages, shown as Fig. 4.

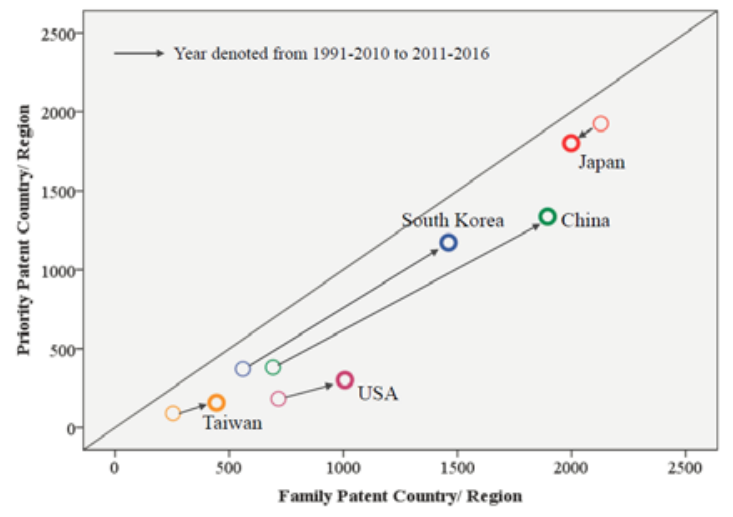

(a) The role shift in period 1991-2010 and 2011-2016

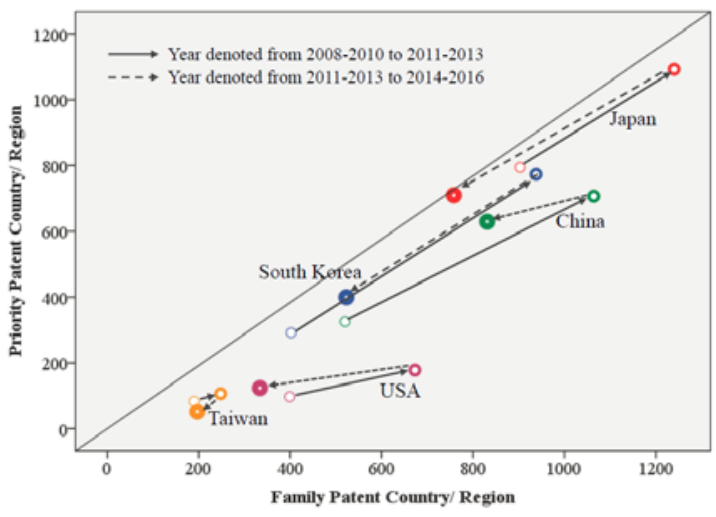

(b) The role shift in period 2008-2010, 2011-2013 and 2014-2016

Fig. 4. The leading countries/ regions in DSSCs in different periods 
The work conducted by Zhou et al. [23] and published in 2014 by using the data from 1991 to 2012 (the data are incomplete for 2011 and 2012, while the data in 2010 are almost complete) figured out the following points: 1) the leading countries were different for each period; 2) the DSSCs patenting concentration spread from Europe to Japan, to the US, and then on to the whole world; 3) Japan and the US are major countries with a lot of DSSCs patents, South Korea has also attracted much attention in recent years.

In the Fig. 4(a) and Fig. 4(b), the x- axis present the respective of patent family country/ regions and the $y$ - axis present the respective of priority country/ regions. Both from the respective of priority country/ regions and patent family country/ regions, the findings partly accord with previous conclusions that Japan win the advantage in the past period, and South Korea plays a more and more important role in the recent years. Because Japan holds an absolute technical advantage in the DSSCs field with outstanding performance in the application of inventions throughout the period and has held the greatest potential market share for the past 20 years. South Korea has also been active in the field since 2008, holding a favorable position until recent period. But the emerging role of China is missed by previous analysis, which mainly due to the rapid growth is hard to predict in the early stage with limited information. In fact, China has played a notable role after 2011 when China's share of patent applications come to increase significantly. In addition, the number of patents that firstly obtain priority in US keep relative stable, almost in the every stage.

Compared with taking the whole stage as a time window, the trend in the recent 3 years can better profile the actual situation afterward, both in 1991-2010 and 2011-2016, shown as Fig. 4(b). Looking at the observations for 2008, we can sense that both China and South Korea have the potential for growth into a promising product market. And, in fact, this prediction is verified by the data for 2011-2016. Based on the trends for 2014-2016, China is likely to retain the greatest proportion of market share in the near future, and China, Japan, and South Korea will continue to be the key players in the technological field of DSSCs. On one hand, it is definitely patenting concentration spread from regions to the whole world; on other hand, the Asia become the most desired patenting target, which is beyond expectation of previous research. For the kind of the omissions and discrepancies in market expansion and application activity, the role shift patterns is mainly affected by the national policy, because government play a more and more important role in introducing and promoting the development of emerging industries. The government's featherbeds stimulate industry vigorous development, it is the "darling" of attention, but when the change of external environment and internal policy changed, the industry fell into the cold winter.

\subsubsection{The alternation of highlighted technological actors}

We now turn to the most prominent organizations in technological exploration and patent applications. In our previous two paper published in 2012, the main patent assignees are indicated. But as the time period used in these papers is inconsistent, so the leading actors and their roles are different. The comparative results of leading patent assignees in DSSCs fields can be seen $n$ Table 3 . 
Table 3. The comparative results of leading patent assignees in DSSCs fields

\begin{tabular}{l|lll}
\hline Source & $\begin{array}{l}\text { Guo, Xu, Huang and Porter } \\
\text { (2012) [18] }\end{array}$ & $\begin{array}{l}\text { Guo, Ma, Porter and Huang } \\
(2012)[56]\end{array}$ & Current research \\
\hline Time span & $1991-2009$ & $1991-2010$ & \\
Patent databases & DWPI & DWPI & 1991-2016 \\
Leading assignees & Samsung SDI Co Ltd (16) & Samsung SDI Co. Ltd (65) & Fujikura Ltd (218) \\
& Konarka Technologies Inc (8) & Nippon Oil Corp (27) & Konica Corp (158) \\
& Sony Corp (6) & Fujikura Ltd (17) & Fuji Film Corp (157) \\
& Fuji Film Corp (6) & Sony Corp (17) & Sony Corp (157) \\
& Nanosolar Inc (6) & Sharp Kk (17) & Samsung Sdi Co Ltd (151) \\
& Nanosys Inc (6) & Dong Jin Semichem Co. & Sharp Kk (144) \\
& & Ltd (16) & Dainippon Printing Co Ltd (133) \\
& & Konarka Technologies Inc. & Dong Jin Semichem Co Ltd \\
& & $(11)$ & (112) \\
\hline
\end{tabular}

The one of works conducted by Guo et al. [18] indicate Samsung Electronics Co Ltd, Konarka Technologies Inc, Fuji Film Corp, Nanosolar Inc, Nanosys Inc and Sony Corp ranked the leading positions when they conducted internal actor analyses for informing a technology delivery system model DSSCs. But one years later, the situation changed, which can be viewed from the other research [56]. Except for Samsung SDI Co Ltd, Konarka Technologies Inc and Sony Corp who still stand at the leading position, Nanosolar Inc and Nanosys Inc are replaced by Fujikura Ltd, Sharp Kk and Dong Jin Semichem Co Ltd. After tracing the message offered by official introduction and commercial report, we find some clues related to their backgrounds and development history. Nanosolar Inc, a developer of solar power technology, used thin film technology to manufacture CIGS solar cells since 2002, but ultimately failed commercially in 2013. Nanosys Inc keep its role in designing products for displays based on quantum dots by developing one of the largest quantum dot patent portfolios with over 200 issued and pending patents worldwide[57]. The use of inorganic semiconductors as effective light sensitizers in a DSSCs configuration have awaken a great interest in the past few years, in opposition to the conventional DSSCs, inorganic quantum dots play a direct role in the recombination process[58]. For Nanosys, quantum dot enhancement film become its development foci, and that might be the most important clue of the role change.

When we looked for the current leading highlighted technological actors in current stage, Fujikura Ltd, Fuji Film Corp, Sony Corp, Samsung Sdi Co Ltd, Sharp Kk and Dong Jin Semichem Co Ltd still keep their competitive advantage in the technology battles and commercial competitions. Konarka Technologies Inc and Nippon Oil Corp are no longer stand out in recent stage. Konarka Technologies Inc, was a solar energy company founded in 2001, obtained the licensee rights to DSSCs technology from the Swiss Federal Institute of Technology (EPFL), a pioneer in DSSCs research. However, this promising company filed for Chapter 7 bankruptcy protection and laid off its approximately 80-member staff in late May 2012 [59]. For the Nippon Oil \& Energy Corporation, a Japanese petroleum company, its main businesses include crude oil, petroleum products and other energy-related activities. In 2008, Japan's Sanyo Electric Co Ltd has agreed to start talks with Nippon Oil Corp over a thin-film solar cell joint venture, and launch a joint company named Sanyo ENEOS solar Co Ltd for the production and sale of thin-film solar panels in 2009. However, Sanyo ENEOS 
Solar has not brought great success for Nippon Oil Corp, and the role of Nippon Oil Corp is replaced by other new comers in DSSCs.

In addition, we not only highlight the leading patent assignees across the whole period of study but also on the emerging actors in relatively recent years. The active technology assignees in 19912010 and 2011-2016 are plotted in Fig. 5. These 13 assignees were selected according to their top-5 ranked performance in the 1991-2010, 2008-2010, 2011-2016, and 2014-2016 periods. The lines in the scatter plots indicate the median values of the assignees. The detailed patent activity information is provided in Table 4 .

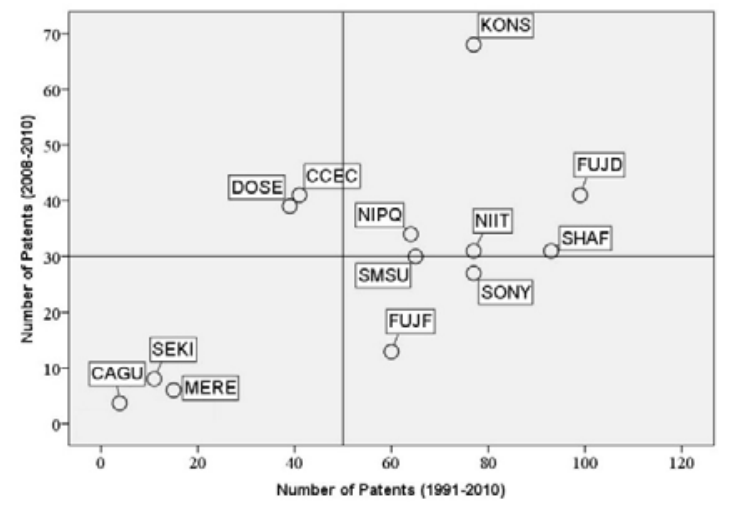

(a) The active technology assignees in 1991-2010

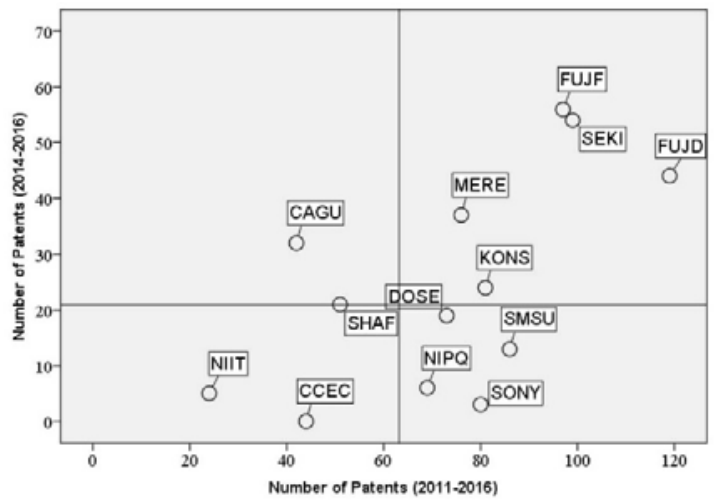

(b) The active technology assignees in 2011-2016

Fig. 5. Scatter plots of the active technology assignees for (a) 1991-2010 and (b) 2011-2016

From our observations of the scatter plots and Table 4, we classified these assignees into three types:

- Leading actors, who are active in every interval including recent years. Fuji Film Corp (FUJF) is the leading patentee in every period, indicating its strong and persistent ability for technological innovation. Other leading patent assignees, such as Konica Corp (KONS) and Fuji Film Corp (FUJF) also performed well in patent activity in the past two decades.

- Declining actors, who performed well in the initial stage but have become relatively inactive in the recent stage. Some have not even applied for patents. Sony Corp (SONY) were rather active in the early stage but in recent years, have gradually lost their advantage, especially over the past three years. The same is true for some other assignees, including Samsung SDI Co Ltd (SMSU), Dainippon Printing Co Ltd (NIPQ), Dong Jin Semichem Co Ltd (DOSE), Dokuritsu Gyosei Hojin Sangyo Gijutsu So (NIIT), and Irico Group Co Ltd (CCEC).

- Emerging actors, who were in the shade at the beginning of development but have performed noticeably better in recent stages. These actors may not have played a core role in the technological market, but they have the potential to impact their particular area in the near future. These assignees include Sekisui Chem Ind Co Ltd (SEKI), followed by Merck Patent Gmbh (MERE) and Shanghai Inst Ceramics Chinese Acad Sci (CAGU). 
Table 4. The Top patent assignees in different periods during 1991-2016

\begin{tabular}{l|c|cccc|c}
\hline \multicolumn{1}{c|}{ Patents assignees } & Records & 1991-2010 & 2008-2010 & 2011-2016 & 2014-2016 & Role \\
\hline Fujikura Ltd (FUJD) & 218 & 99 & 41 & 119 & 44 & Leading \\
Konica Corp (KONS) & 158 & 77 & 68 & 81 & 24 & Leading \\
Fuji Film Corp (FUJF) & 157 & 60 & 13 & 97 & 56 & Leading \\
Sony Corp (SONY) & 157 & 77 & 27 & 80 & 3 & Declining \\
Samsung SDI Co Ltd (SMSU) & 151 & 65 & 30 & 86 & 13 & Declining \\
Sharp Kk (SHAF) & 144 & 93 & 31 & 51 & 21 & Leading \\
Dainippon Printing Co Ltd (NIPQ) & 133 & 64 & 34 & 69 & 6 & Declining \\
Dong Jin Semichem Co Ltd & 112 & 39 & 39 & 73 & 19 & Declining \\
(DOSE) & 110 & 11 & 8 & 99 & 54 & Emerging \\
Sekisui Chem Ind Co Ltd (SEKI) & 101 & 77 & 31 & 24 & 5 & Declining \\
Dokuritsu Gyosei Hojin Sangyo & & & & & & \\
Gijutsu So (NIIT) & 91 & 15 & 6 & 76 & 37 & Emerging \\
Merck Patent Gmbh (MERE) & 85 & 41 & 41 & 44 & 0 & Declining \\
Irico Group Co Ltd (CCEC) & 46 & 4 & 4 & 42 & 32 & Emerging \\
Shanghai Inst Ceramics Chinese & & & & & & \\
Acad Sci (CAGU) & & & & & & \\
\hline
\end{tabular}

Look back to the discrepant role changes of leading patent assignees in DSSCs, we can see the notable role in previous research has been changed a lot: Samsung Electronics Co Ltd and Sony Corp active in patent activity over the next few years, but present a declining trend in most recent years; Konarka Technologies Inc and Nanosolar Inc came across the bankruptcy when facing various kind troubles in terms of technological bottleneck, slow-development cycle, complex production problems and the external competitors; Nanosys Inc paid its most efforts to quantum dot sensitized solar cell rather than dye sensitized solar cell. For the super companies, such as Samsung SDI Co Ltd, Sony Corp and Fuji Film Corp, they have enough capacity to develop and update technologies, and it is relatively easy for them to obtain competitive advantage. But for the domain emerging actors, such as Konarka Technologies Inc and Nanosolar Inc, their developments are heavily depend on the funding from venture capital firms. Therefore, when we monitor such players, we cannot fully defined by this empirical information, but also care about the company background and further check and enrich this 'competitive technical intelligence' through human expertise.

\subsection{Validate enhanced technology detection}

\subsubsection{The transformation in distributed technology fields}

Another essential aspect of technology forecasting is understanding a technical domain at the right level of aggregation. The systematic properties of a patent classification system, such as International Patent Classification (IPC), is always used to identify the specific detailed technological areas that make up different technologies and industries.

The previous work conducted by Zhou et al. published in 2014 [23] used 8-digit IPCs to trace the evolutionary path for DSSCs by dividing patent records into several time intervals and identified the subordinate research areas for different time intervals. Based on the revealed linkages between these key sub-technologies, they linked the same IPC numbers to different time intervals. These 
demonstrate the gradual evolutionary pathways for sub-technologies over time. The main opinions and predictions are summarized in Table 5 .

Table 5. Main analyses and predictions of sub-technology fields using 8-digit IPCs

\begin{tabular}{|c|c|c|}
\hline IPC & Main technology content & Analyses and predictions \\
\hline H01L-31/04 & $\begin{array}{l}\text { Semiconductor devices } \\
\text { adapted as photovoltaic }[\mathrm{PV}] \\
\text { conversion devices. }\end{array}$ & $\begin{array}{l}\text { It is a core research area within the DSSCs industry and has } \\
\text { maintained a rapid growth rate. There is a high possibility that it will } \\
\text { stay in the leading position in this industry for several years to come. }\end{array}$ \\
\hline H01M-14/00 & $\begin{array}{l}\text { Electrochemical current or } \\
\text { voltage generators (in energy } \\
\text { conversion processes). }\end{array}$ & Same with H01L-031/04. \\
\hline H01G-09/20 & Light-sensitive devices. & $\begin{array}{l}\text { It changes steadily and advances to a different level with each stage. } \\
\text { The research attention has increased at a relatively constant rate. }\end{array}$ \\
\hline H01L-31/042 & $\begin{array}{l}\text { PV modules or arrays of } \\
\text { single PV cells. }\end{array}$ & It has become a popular research area. \\
\hline H01L-51/42 & $\begin{array}{l}\text { The technology that employs } \\
\text { organic materials as the active } \\
\text { part for solid state devices. }\end{array}$ & It is an emerging sub-technology, is rapidly developing. \\
\hline C09B-23/00 & $\begin{array}{l}\text { Methine or polymethine dyes, } \\
\text { e.g. cyanine dyes. }\end{array}$ & $\begin{array}{l}\text { It increases slowly but steadily. Nevertheless, this is an important } \\
\text { area for DSSCs, so attention should be paid to this subfield. }\end{array}$ \\
\hline H01M-10/40 & $\begin{array}{l}\text { Organic electrolyte } \\
\text { (transferred to H01M 10/05- } \\
\text { H01M 10/0587). }\end{array}$ & $\begin{array}{l}\text { It emerges during the period of } 2000-2003 \text {, but this technology nearly } \\
\text { disappears after } 2008 \text {. }\end{array}$ \\
\hline
\end{tabular}

Note: Based on the paper indicated, the data for the time period from 1991 to 2009 are accurate, but for the years 2010 and 2011, the data values are estimated. The evolutionary trend map for DSSCs technology includes these estimated values.

In table 5, 7 IPCs are list as the heighted sub-technology field. As the H01M-10/40 is transferred to H01M 10/05-H01M 10/0587 and no longer existed in the 2010 edition IPC scheme, so the other 6 IPCs are selected to compare the real situation and previous opinions, as shown in Fig. 6(a). H01L31/04 (semiconductor devices adapted as photovoltaics) H01M-14/00 (electrochemical current or voltage generators) share the similar trends that they keep leading positions until 2012 and then decrease to a very low amount in 2016. There is no doubt they are the core research area within the DSSCs industry, but they cannot hold the leading position in the several years to come. H01G-09/20 (light-sensitive devices), as previous judged, advances at a relatively continuous growth rate and become the most heighted IPC in the most recent years. The H01L-31/042 (PV modules or arrays of single PV cells) stands out for its impressive increase in 2013 and 2014, but comes across a sharp drop subsequently. H01L-51/42 (employs organic materials as the active part for solid state devices) disappoints us that it has not reached a rapidly develop, and C09B-23/00 (methine or polymethine dyes, e.g. cyanine dyes has not paid enough attention yet. 


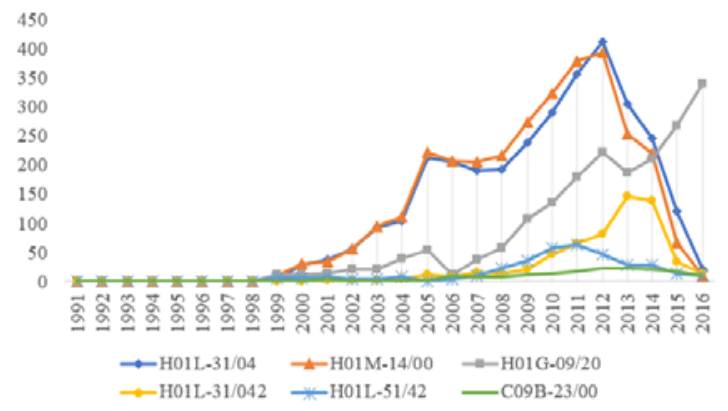

(a) The heighted IPCs in previous research

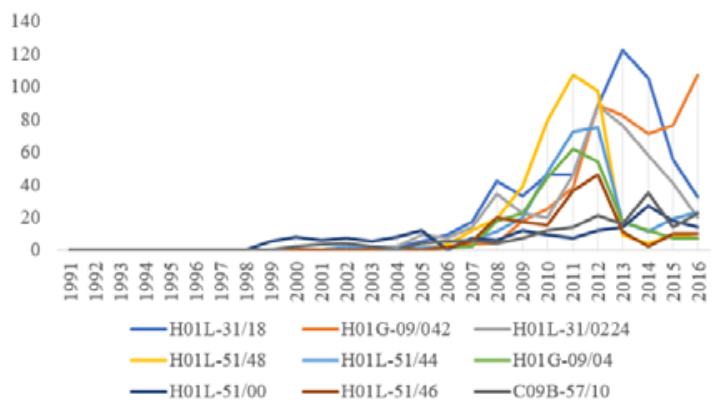

(b) The other emerging IPCs from current view

Fig. 6. The publication trends of leading IPCs in DSSCs during 1991-2016

In addition to the IPCs heighted by previous research, some emerging IPCs are need to be paid enough attention, shown as in Fig. 6(b). The criteria for choosing target IPCs is based on the number of patents for the chosen IPCs should be 160 or more, which closes to minimum amount of IPCs presented in Fig. 6(a). It indicates that most these chosen IPCs are emerge after 2005, except for H01L-51/00 (Solid state devices using organic materials as the active part). H01L, which relates to semiconductor devices, is the biggest subordinate emerging research area in the field of DSSCs and 6 IPCs belongs to this subclass, including H01L-31/18 (Processes or apparatus specially adapted for the manufacture or treatment of these devices or of parts thereof semiconductor devices), H01L31/0224 (Electrodes of Semiconductor devices), H01L-51/48 (Processes or apparatus specially adapted for the manufacture or treatment of such devices or of parts thereof solid state devices), H01L-51/44 (Details of solid state devices), H01L-51/46 (Selection of organic materials), and H01L31/18. Besides, H01G relates to basic electric elements such as capacitors, rectifiers, switching, lightsensitive or temperature-sensitive devices of the electrolytic type is another noteworthy subclass, including H01G-09/04 (Electrodes of electrolytic capacitors) and H01G-09/04 (Characterised by the material of electrodes). Specially, H01G-09/042 is the unique IPC that still keeps the growth trend in term of patent number in 2015 and 2016.

In general, most evolutionary trend for sub-technology fields are heavily depend on the technology life cycle. In the early exploring stage, the foci so scattered and hard to pinpoint the potential components. When it enters the growth stages, the core devices, processes and apparatus get increased attention to promote the whole technology forward. When it comes to the maturity phase, the overall growth trends may suffer an obvious decrease but the material-related fields remain promising prospect. Therefore, when we make a prediction and judgment, the development stages can be carefully observed and the main technology functions are necessary to be identified and distinguished. Moreover, the new combinations of technologies (existing and/ or emerging) and many socio-economic forces (e.g., fluctuations in demand, regulations, ethical or environmental concerns) may also change a development trajectory and technology filed evolutionary trend.

\subsubsection{The evolution of potential technology foci}

One of our previous analyses on DSSCs using the FIP approach provided a framework for shaping the potential innovation pathways over a timeframe. This framework helped to locate the obstacles and opportunities that are likely to facilitate or inhibit progress along a particular pathway 
[56]. This framework sets out a prescribed procedure for analysis: the literature is reviewed first, followed by an initial database search. The database search results are text mined to identify local expertise. Face-to-face interviews with those experts provide input for the first evaluation of the analyses. Then, a workshop is conducted to focus on mapping likely innovation avenues following the process described and demonstrated by Robinson and Propp [2]. These expert workshops involve a wider spectrum of experts and stakeholders for more extended interactions (e.g., a full day). A key element of many future-oriented technology analyses is the expert forecasting workshop. These workshops provide a means of combining codified and tacit knowledge to explore the plausibility of various technology options. They also provide key intelligence for assessing the potential innovations that may stem from each option [60]. In tandem, a multi-path map of the technology's future course is developed - in our case DSSCs. Such visualizations stimulate workshop interactions and create a framework for drawing out the intelligence held by the experts in the workshop - a scaffold upon which to locate their knowledge. The main ideas of the results from the analysis in [58] are presented in Table 6.

Table 6. The ingredients of the multipath exploration for DSSCs

\begin{tabular}{|c|c|c|c|}
\hline Goals & Present $^{a}$ & Short/medium term & Long term \\
\hline Envisioned application areas & Grid-connected & Off-grid & Personal product \\
\hline $\begin{array}{l}\text { Anticipated potential product } \\
\text { platforms }\end{array}$ & $\begin{array}{l}\text { Conventional solar cells; } \\
\text { Sillicon thin-film solar } \\
\text { cells }\end{array}$ & $\begin{array}{l}\text { 3D solar cells; } \\
\text { Nanoparticle-based solar cells }\end{array}$ & $\begin{array}{l}\text { Organic solar cells; } \\
\text { Quantum dot solar } \\
\text { cells }\end{array}$ \\
\hline $\begin{array}{l}\text { Functionalities expected to } \\
\text { made available }\end{array}$ & $\begin{array}{l}\text { A Large surface area could } \\
\text { increase light absorption; } \\
\text { Provide new film } \\
\text { deposition methods to } \\
\text { reduce cost }\end{array}$ & $\begin{array}{l}\text { Large Surface area could help } \\
\text { charge separation; } \\
\text { Multiple excition generation } \\
\text { (MEG) }\end{array}$ & $\begin{array}{l}\text { Tailor optical } \\
\text { properties through its } \\
\text { size }\end{array}$ \\
\hline $\begin{array}{l}\text { Nanostructures that are } \\
\text { expected to be applied to } \\
\text { solar cells }\end{array}$ & $\begin{array}{l}\text { Nanoparticle; } \\
\text { Quantum dot }\end{array}$ & Nanowise; Carbon nanotubes & \\
\hline Advances in material R\&D & $\begin{array}{l}\text { Titanium dioxide }(\mathrm{TiO} 2) \text {; } \\
\text { Zinc oxide }(\mathrm{ZnO}) ; \\
\text { Tin dioxide }(\mathrm{SnO} 2)\end{array}$ & $\begin{array}{l}\text { Cadmium sulphide (Cds); } \\
\text { Copper indium diselenide } \\
\text { (CIS); } \\
\text { Cadmium Telluride (CdTe) }\end{array}$ & \\
\hline
\end{tabular}

a. Note: Here, "present" means that time is around 2010.

In this paper, we attempt to validate the results previously derived based on the latest dataset. Usually, the "what" question is especially challenging. Some fielded records contain helpful content, such as keywords in paper abstracts and classification codes for patents [61]. Hence, we first applied natural language processing (NLP) to extract terms and words in the merged titles and abstract fields of patents. We then followed "term clumping" steps to clean and consolidate topical content, mainly using a combination of thesauri and fuzzy matching routines [62]. After selecting the main technology foci in four DSSCs sub-technologies, we made a matrix of these terms by publication year. Here, we only care about the materials and products in DSSCs for the comparisons and updates.

In terms of the advances in materials $\mathrm{R} \& \mathrm{D}$, the main technology foci of DSSCs materials in four sub-technologies for the period of 2001-2016 are presented in detail in Fig. 7. The color in the 
corresponding grid indicates the relative degree of boom for the whole period. From red to green, the degree is in descending order. We established that among the various nano-structured materials that are used as a semiconductor layer in DSSCs photoanodes, titanium dioxide (TiO2), zinc oxide ( $\mathrm{ZnO}$ ), tin dioxide ( $\mathrm{SnO} 2)$ are still the most important materials, continuing from the early stage to now. But the developmental level of cadmium sulfide (Cds), copper indium diselenide (CIS), and cadmium telluride (CdTe) fell behind our previous predictions. In addition, we developed a sense that previous forecasts appeared rough, with few detailed messages, and were hard to trace. Thus, the time-seriesbased examination of sub-technologies offers an inspiring perspective to enhance forecasting for potential technology foci.

\begin{tabular}{|c|c|c|c|c|c|c|c|c|c|c|c|c|c|c|c|c|}
\hline Technology & 2001 & 2002 & 2003 & 2004 & 2005 & 2006 & 2007 & 2008 & 2009 & 2010 & 2011 & 2012 & 2013 & 2014 & 2015 & 2016 \\
\hline Titanium dioxide & 13 & 12 & 30 & 46 & 69 & 51 & 72 & 77 & 156 & 168 & 215 & 243 & 212 & 226 & 122 & 111 \\
\hline Zinc oxide & 4 & 6 & 6 & 9 & 23 & 25 & 24 & 38 & 84 & 86 & 105 & 92 & 70 & 92 & 39 & 30 \\
\hline Tin oxide & 2 & 5 & 9 & 5 & 18 & 26 & 13 & 19 & 43 & 56 & 47 & 57 & 42 & 53 & 31 & 17 \\
\hline Fluorine-doped tin oxide & 0 & 1 & 1 & 4 & 9 & 11 & 12 & 16 & 42 & 53 & 47 & 64 & 40 & 47 & 30 & 49 \\
\hline Indium tin oxide & 2 & 1 & 1 & 1 & 16 & 23 & 11 & 21 & 42 & 36 & 43 & 44 & 25 & 45 & 26 & 36 \\
\hline Silicon oxide & 0 & 2 & 0 & 4 & 3 & 5 & 2 & 9 & 17 & 15 & 26 & 36 & 22 & 29 & 12 & 11 \\
\hline Zirconium oxide & 1 & 3 & 1 & 4 & 8 & 6 & 5 & 5 & 19 & 13 & 25 & 25 & 23 & 26 & 9 & 9 \\
\hline Niobium oxide & 1 & 3 & 2 & 4 & 10 & 10 & 9 & 7 & 27 & 12 & 23 & 23 & 19 & 16 & 3 & 5 \\
\hline Magnesium oxide & 0 & 1 & 0 & 1 & 3 & 4 & 4 & 5 & 16 & 16 & 26 & 31 & 19 & 18 & 11 & 8 \\
\hline Oxide semiconductor electrode & 1 & 3 & 4 & 6 & 3 & 5 & 9 & 8 & 14 & 3 & 11 & 13 & 7 & 5 & 4 & 1 \\
\hline Copper-indium-gallium-selenium & 0 & 0 & 0 & 0 & 0 & 3 & 0 & 0 & 6 & 6 & 9 & 9 & 18 & 14 & 4 & 9 \\
\hline Antimony dope tin oxide & 0 & 0 & 0 & 1 & 3 & 1 & 2 & 4 & 12 & 8 & 5 & 9 & 2 & 11 & 8 & 3 \\
\hline Gallium oxide-zinc oxide & 0 & 0 & 0 & 0 & 1 & 2 & 3 & 1 & 6 & 8 & 12 & 7 & 4 & 6 & 8 & 3 \\
\hline Yttrium oxide & 0 & 0 & 0 & 0 & 2 & 1 & 1 & 2 & 8 & 3 & 6 & 16 & 7 & 6 & 5 & 1 \\
\hline Calcium oxide & 0 & 0 & 0 & 0 & 0 & 2 & 0 & 0 & 3 & 10 & 12 & 7 & 7 & 7 & 4 & 5 \\
\hline Lanthanum oxide & 0 & 0 & 0 & 0 & 4 & 2 & 1 & 2 & 9 & 4 & 4 & 14 & 4 & 6 & 1 & 2 \\
\hline Antimony oxide & 1 & 0 & 1 & 2 & 2 & 2 & 1 & 2 & 2 & 2 & 7 & 3 & 8 & 5 & 7 & 0 \\
\hline Aluminum zinc oxide & 0 & 0 & 0 & 0 & 1 & 1 & 1 & 1 & 0 & 6 & 10 & 10 & 1 & 6 & 1 & 2 \\
\hline Cerium oxide & 0 & 0 & 0 & 0 & 1 & 0 & 1 & 2 & 3 & 1 & 2 & 5 & 10 & 3 & 2 & 4 \\
\hline Indium zinc oxide & 0 & 0 & 0 & 0 & 1 & 0 & 0 & 1 & 1 & 5 & 6 & 3 & 1 & 6 & 3 & 0 \\
\hline Lithium oxide & 0 & 0 & 0 & 0 & 0 & 1 & 0 & 0 & 0 & 1 & 3 & 3 & 3 & 4 & 4 & 3 \\
\hline Stibium-doped tin oxide & 0 & 0 & 0 & 0 & 0 & 0 & 0 & 1 & 0 & 0 & 1 & 0 & 0 & 0 & 0 & 0 \\
\hline
\end{tabular}

Fig. 7 (a). The main technology foci of DSSCs photoanode in 2001-2016

\begin{tabular}{|l|c|c|c|c|c|c|c|c|c|c|c|c|c|c|c|c|}
\hline Technology & 2001 & 2002 & 2003 & 2004 & 2005 & 2006 & 2007 & 2008 & 2009 & 2010 & 2011 & 2012 & 2013 & 2014 & 2015 & 2016 \\
\hline Organic dye & 1 & 1 & 5 & 11 & 9 & 9 & 6 & 8 & 18 & 21 & 23 & 23 & 39 & 30 & 15 & 10 \\
\hline Ruthenium complex dye & 3 & 1 & 0 & 0 & 1 & 0 & 4 & 2 & 7 & 9 & 8 & 7 & 6 & 5 & 5 & 6 \\
\hline Porphyrin-based dye & 1 & 0 & 0 & 2 & 2 & 4 & 2 & 3 & 5 & 4 & 1 & 11 & 7 & 6 & 3 & 6 \\
\hline Cyanine dye & 0 & 0 & 0 & 2 & 2 & 2 & 2 & 3 & 2 & 5 & 4 & 6 & 5 & 3 & 2 & 2 \\
\hline N719 dye & 0 & 0 & 0 & 0 & 0 & 0 & 0 & 0 & 2 & 6 & 6 & 8 & 4 & 7 & 4 & 8 \\
\hline Solid state dye & 0 & 0 & 0 & 0 & 0 & 1 & 1 & 3 & 0 & 7 & 7 & 7 & 4 & 5 & 7 & 2 \\
\hline Metal complex dye & 3 & 1 & 2 & 1 & 2 & 2 & 0 & 1 & 1 & 2 & 2 & 3 & 3 & 10 & 2 & 6 \\
\hline Fluorescent dye & 1 & 2 & 0 & 2 & 1 & 3 & 6 & 4 & 4 & 4 & 2 & 0 & 3 & 0 & 0 & 0 \\
\hline Merocyanine dye & 2 & 0 & 2 & 1 & 1 & 4 & 0 & 0 & 3 & 4 & 3 & 5 & 5 & 1 & 1 & 2 \\
\hline Black dye & 0 & 0 & 0 & 0 & 0 & 2 & 0 & 2 & 3 & 4 & 3 & 0 & 1 & 6 & 2 & 0 \\
\hline Phenothiazine dye & 0 & 0 & 0 & 0 & 0 & 0 & 0 & 1 & 0 & 0 & 3 & 5 & 2 & 4 & 1 & 2 \\
\hline Natural dye & 0 & 1 & 0 & 0 & 0 & 0 & 0 & 0 & 2 & 0 & 2 & 2 & 3 & 2 & 4 & 0 \\
\hline Fluorine based dye & 0 & 0 & 0 & 0 & 0 & 0 & 0 & 0 & 0 & 1 & 3 & 2 & 1 & 0 & 2 & 0 \\
\hline N3 dye & 0 & 0 & 0 & 0 & 0 & 0 & 0 & 0 & 2 & 1 & 0 & 0 & 2 & 1 & 2 & 0 \\
\hline
\end{tabular}

Fig. 7 (b). The main technology foci of DSSCs sensitizer in 2001-2016

\begin{tabular}{|c|c|c|c|c|c|c|c|c|c|c|c|c|c|c|c|c|}
\hline Technology & 2001 & 2002 & 2003 & 2004 & 2005 & 2006 & 2007 & 2008 & 2009 & 2010 & 2011 & 2012 & 2013 & 2014 & 2015 & 2016 \\
\hline Solid electrolyte & 0 & 0 & 2 & 4 & 4 & 8 & 3 & 4 & 11 & 11 & 18 & 15 & 9 & 5 & 4 & 9 \\
\hline Liquid electrolyte & 0 & 0 & 0 & 0 & 3 & 0 & 2 & 1 & 5 & 4 & 6 & 4 & 6 & 8 & 1 & 4 \\
\hline Non-aqueous electrolyte & 0 & 0 & 0 & 3 & 3 & 5 & 2 & 1 & 3 & 1 & 1 & 1 & 1 & 1 & 0 & 1 \\
\hline Polymer electrolyte & 0 & 0 & 0 & 2 & 1 & 0 & 1 & 3 & 0 & 2 & 1 & 4 & 3 & 2 & 1 & 0 \\
\hline Gel electrolyte & 0 & 0 & 0 & 0 & 0 & 0 & 1 & 2 & 0 & 0 & 2 & 2 & 2 & 1 & 1 & 0 \\
\hline Gel-like electrolyte & 0 & 1 & 0 & 0 & 0 & 0 & 0 & 0 & 0 & 2 & 3 & 2 & 1 & 0 & 0 & 1 \\
\hline Quasi-solid electrolyte & 0 & 0 & 0 & 0 & 1 & 0 & 3 & 1 & 0 & 0 & 0 & 1 & 1 & 1 & 1 & 0 \\
\hline Salt electrolyte & 0 & 0 & 0 & 0 & 0 & 0 & 1 & 0 & 5 & 0 & 0 & 1 & 1 & 0 & 0 & 0 \\
\hline
\end{tabular}

Fig. 7 (c). The main technology foci of DSSCs electrolyte in 2001-2016 


\begin{tabular}{|c|c|c|c|c|c|c|c|c|c|c|c|c|c|c|c|c|}
\hline Technology & 2001 & 2002 & 2003 & 2004 & 2005 & 2006 & 2007 & 2008 & 2009 & 2010 & 2011 & 2012 & 2013 & 2014 & 2015 & 2016 \\
\hline Tungsten electrode & 2 & 2 & 2 & 3 & 14 & 6 & 15 & 12 & 33 & 17 & 28 & 46 & 32 & 41 & 11 & 28 \\
\hline Molybdenum electrode & 2 & 0 & 0 & 1 & 4 & 3 & 2 & 2 & 10 & 6 & 12 & 19 & 18 & 18 & 11 & 6 \\
\hline Platinum electrode & 0 & 0 & 1 & 1 & 2 & 1 & 3 & 4 & 11 & 19 & 7 & 9 & 16 & 8 & 10 & 13 \\
\hline Metal electrode & 0 & 0 & 0 & 0 & 0 & 2 & 1 & 3 & 3 & 8 & 10 & 16 & 13 & 5 & 2 & 1 \\
\hline Carbon electrode & 0 & 0 & 0 & 2 & 1 & 0 & 1 & 2 & 2 & 5 & 2 & 3 & 5 & 3 & 1 & 1 \\
\hline Inorganic compound electrode & 0 & 0 & 1 & 0 & 0 & 1 & 0 & 2 & 0 & 2 & 6 & 4 & 4 & 5 & 1 & 1 \\
\hline Conductive polymer electrode & 0 & 0 & 0 & 0 & 1 & 0 & 1 & 0 & 1 & 2 & 0 & 0 & 0 & 1 & 1 & 2 \\
\hline Hybrid electrode & 0 & 0 & 0 & 0 & 0 & 0 & 0 & 1 & 0 & 0 & 0 & 1 & 2 & 1 & 0 & 0 \\
\hline
\end{tabular}

Fig. 7 (d). The main technology foci of DSSCs counter-electrode in 2001-2016

At the level of DSSCs products, previous analyses (Shown in Table 6) indicated that 3D solar cells and nanoparticle-based solar cells would likely emerge over the short-to-medium term and that organic solar cells and quantum dot solar cells would blossom over the longer term. Fig. 8 presents the annual trends for nano-enhanced solar cell-related products. As shown, organic solar cells grew rapidly from 2008 but began to decrease from 2013, rather than continuing to develop. In fact, organic solar cell research began 30 years ago but has attracted significantly more scientific and economic interest over the last decade, triggered by a rapid increase in power conversion efficiency [63]. However, as many other new types of solar cells have emerged in the most recent years, its growth has turned into decline. Nanoparticle-based solar cells indeed saw remarkable gains over the past several years. In addition, the predicted trend for silicon thin-film solar cells and quantum dot solar cells were well informed and projected at the right levels. Nanoparticle cells have since seen a decline, but quantum dot solar cells have maintained a stable growth rate with a high possibility that they will continue to develop and maintain an important position in the future. The development of 3D solar cells has not met expectations and has not been widely explored, even though it shows promise for improvements in conversion efficiency by absorbing virtually all of the light.

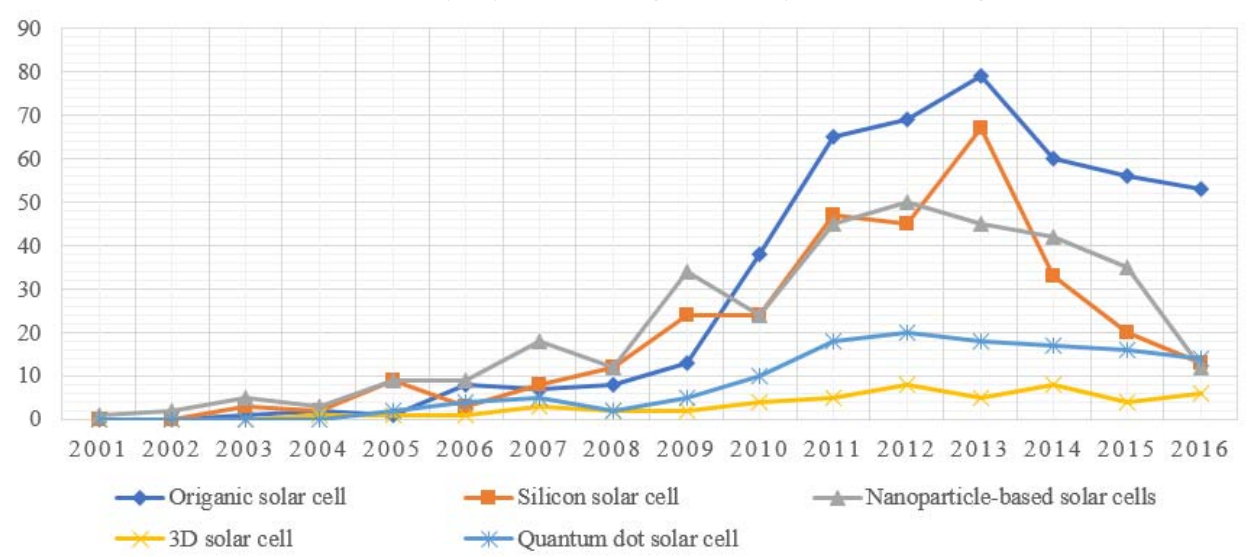

Fig. 8. The growing trends of nano-enhanced solar cell-related products based on insights from DSSCs patents

Tracing the innovation pathways of potential technology foci offers an important tool set to approach real improvements in forecasting emerging topics and their potential applications. However, the comparative results show there is still a gap that cannot meet the expectation. On one hand, previous work like [58] lacks the effective method to provide appropriate level content when facing the abstract record results that pertain to a particular technology. On the other hand, combining empirical with expert analyses seems promising to address "what" issues, but the clumped phrases 
are need to appropriately provided for expert review to point out key topics and technologies for further scrutiny. Therefore, an effective method to extract technical content for technological intelligence turns out to be an alternative solution. For example, topic modeling appears to have utility to reduce the cycle time, the complexity, and analyst input required for a technology analysis [61]. The approach presents an attractive scalability, suggesting the possibility to move beyond abstracts into full text analysis. However, such a method based on analytical software can offer help in most time consuming step, but it still be required to produce an effective assessment by human efforts and domain knowledge.

\section{Discussion AND CONCLUSIONS}

The paper proposes a framework for assessing data-driven technology forecasting and uses that framework to revisit our previous research on DSSCs using an updated patent dataset. After addressing the technology life cycle to locate whether the technology keep the phase as previous indicated or enter the following develop phase, we compare the basic technology profiling and validate enhanced technology detection. We conducted a comparative empirical study to contrast the results in terms of the technology's stage in its country/regional focus and the prominent actors and attempted to answer what's role change among leading, emerging and declining status in various stages? In addition, we further explore the evolutions of technological fields and technological foci to figure out what are the differences and what causes the differences when the results shows that some preceding predictions correspond to actual performance; but others do not.

We conclude that a number of factors account for these differences: First, data quality is the foundation of data-based technology forecasting, including its veracity and completeness. Veracity can be enhanced by using an appropriate search strategy on a reliable data source. But insufficient data is an innate problem that cannot be totally avoided. For example, inaccuracies in our forecasts on DSSCs's stage in its lifecycle in a previous study were because we could not always obtain the most recent data. Therefore, frequent monitoring is an alternative way to deal with this imperfection. Second, technology forecasting methods are empirical substitutes for the theory of sociotechnical change, and no approach is perfect. We cannot rely heavily on a single method, but rather aggregate diverse approaches with complementary strengths need to be used to mitigate the negative effects caused by each method alone. Third, future-oriented analyses are characterized by complexity and dynamism, so less emphasis needs to be placed on the leading actors or trends in the current stage, in favor of the emergent actors and trends, which are more likely to influence the near future.

Although the development of technology follows a certain path dependence, the evolutionary trend sometimes evolved in a jumping way rather than a gradual due to some uncertain external factors, and accidental random mutation factors will affect the evolutional path. In the "Managing the present from the future" section of Forecasting and Management of Technology, the authors give a dozen recommendations for technology forecasting. We agree with their thesis that, "The future is very much an open system with fuzzy, impenetrable boundaries in both space and time. Images of the future must accommodate uncertainty and be adaptable, yet provide focal points to guide present actions." [53] Technology forecasting offers a relevant opportunity in this direction and is currently an up-and-coming area of research. Forecasters can learn much from re-analyzing past predictions, 
and there is value in paying more attention to the retrospect by assessing what we have done as a means to improving what we should and will do going forward.

\section{ACKNOWLEDGMENTS}

We acknowledge support from the Junior Fellowships of CAST Advanced S\&T Think-tank Program (Grant No. DXB-ZKQN-2017-020), the National Natural Science Foundation of China (Grant No. 71503020), and the US National Science Foundation (Award No. 1527370 and 71874013 ). The findings and observations contained in this paper are those of the authors and do not necessarily reflect the views of the supporters.

\section{REFERENCES}

[1] D. Rotolo, I. Rafols, M.M. Hopkins, L. Leydesdorff, Strategic intelligence on emerging technologies: Scientometric overlay mapping, Journal of the Association for Information Science and Technology, 68 (2017) 214-233.

[2] D.K.R. Robinson, T. Propp, Multi-path mapping for alignment strategies in emerging science and technologies, Technol. Forecast. Soc. Chang., 75 (2008) 517-538.

[3] D.K.R. Robinson, L. Huang, Y. Guo, A.L. Porter, Forecasting Innovation Pathways (FIP) for new and emerging science and technologies, Technol. Forecast. Soc. Chang., 80 (2013) 267-285.

[4] A.L. Porter, S.W. Cunningham, Tech mining: Exploiting new technologies for competitive advantage, John Wiley \& Sons, Inc., New York, 2005.

[5] A.L. Porter, Y. Guo, D. Chiavatta, Tech mining: text mining and visualization tools, as applied to nanoenhanced solar cells, Wiley Interdiscip. Rev.-Data Mining Knowl. Discov., 1 (2011) 172-181.

[6] A.L. Porter, S.W. Cunningham, A. Sanz, Advancing the forecasting innovation pathways approach: Hybrid and electric vehicles case, International Journal of Technology Management, 69 (2015) 275-300.

[7] A.T. Roper, S.W. Cunningham, A.L. Porter, T.W. Mason, F.A. Rossini, J. Banks, Technology Forecasting, in: Forecasting and Management of Technology, John Wiley \& Sons, Inc., New York, 2011, pp. 15-39.

[8] M.L. Parisi, S. Maranghi, R. Basosi, The evolution of the dye sensitized solar cells from Grätzel prototype to up-scaled solar applications: A life cycle assessment approach, Renewable and Sustainable Energy Reviews, 39 (2014) 124-138.

[9] J.B. Baxter, Commercialization of dye sensitized solar cells: Present status and future research needs to improve efficiency, stability, and manufacturing, J. Vac. Sci. Technol. A, 30 (2012) 020801020801-020819.

[10] J. Youtie, A.L. Porter, P. Shapira, N.C. Newman, Lessons from ten years of nanotechnology bibliometric analysis, in: OECD Blue Sky Forum on Science and Innovation Indicators, Ghent, Belgium, 2016.

[11] Y. Guo, L. Huang, A.L. Porter, The research profiling method applied to nano-enhanced, thinfilm solar cells, R\&D Management, 40 (2010) 195-208.

[12] L. Huang, Y. Guo, Z. Peng, A.L. Porter, Characterising a technology development at the stage of early emerging applications: nanomaterial-enhanced biosensors, Technol. Anal. Strateg. Manage., 23 (2011) 527-544.

[13] T.T. Ma, A.L. Porter, Y. Guo, J. Ready, C. Xu, L.D. Gao, A technology opportunities analysis model: applied to dye-sensitised solar cells for China, Technol. Anal. Strateg. Manage., 26 (2014) 87-104.

[14] X.F. Wang, P.J. Qiu, D.H. Zhu, L. Mitkova, M. Lei, A.L. Porter, Identification of technology development trends based on subject-action-object analysis: The case of dye-sensitized solar cells, Technol. Forecast. Soc. Chang., 98 (2015) 24-46. 
[15] J. Guo, X. Wang, Q. Li, D. Zhu, Subject-action-object-based morphology analysis for determining the direction of technological change, Technol. Forecast. Soc. Chang., 105 (2016) 2740.

[16] X.F. Wang, M. Huang, H.Y. Wang, M. Lei, D.H. Zhu, J. Ren, M. Jabeen, International Collaboration Activity Index: Case study of dye-sensitized solar cells, J. Informetr., 8 (2014) 854862.

[17] X.F. Wang, R.R. Li, S.M. Ren, D.H. Zhu, M. Huang, P.J. Qiu, Collaboration network and pattern analysis: case study of dye-sensitized solar cells, Scientometrics, 98 (2014) 1745-1762.

[18] Y. Guo, C. Xu, L. Huang, A. Porter, Empirically informing a technology delivery system model for an emerging technology: illustrated for dye-sensitized solar cells, R D Manage., 42 (2012) 133149.

[19] Y. Guo, T.T. Ma, A.L. Porter, Innovation Risk Path Assessing for a Newly Emerging Science and Technology: Illustrated for Dye-Sensitized Solar Cells, in: E. Ndubuisi, I. Nazrul (Eds.) Disruptive Technologies, Innovation and Global Redesign: Emerging Implications, IGI Global, Hershey, PA, USA, 2012, pp. 12-26.

[20] L. Huang, Y. Zhang, Y. Guo, D.H. Zhu, A.L. Porter, Four dimensional Science and Technology planning: A new approach based on bibliometrics and technology roadmapping, Technol. Forecast. Soc. Chang., 81 (2014) 39-48.

[21] Y. Zhang, X. Zhou, A.L. Porter, J.M.V. Gomila, How to combine term clumping and technology roadmapping for newly emerging science \& technology competitive intelligence: "problem \& solution" pattern based semantic TRIZ tool and case study, Scientometrics, 101 (2014) 1375-1389.

[22] Y. Zhang, X. Zhou, A.L. Porter, J.M.V. Gomila, A. Yan, Triple Helix innovation in China's dyesensitized solar cell industry: hybrid methods with semantic TRIZ and technology roadmapping, Scientometrics, 99 (2014) 55-75.

[23] X. Zhou, Y. Zhang, A.L. Porter, Y. Guo, D.H. Zhu, A patent analysis method to trace technology evolutionary pathways, Scientometrics, 100 (2014) 705-721.

[24] Y. Zhang, D.K.R. Robinson, A.L. Porter, D.H. Zhu, G.Q. Zhang, J. Lu, Technology roadmapping for competitive technical intelligence, Technol. Forecast. Soc. Chang., 110 (2016) 175-186.

[25] T.-S. Cho, H.-Y. Shih, Patent citation network analysis of core and emerging technologies in Taiwan: 1997-2008, Scientometrics, 89 (2011) 795-811.

[26] N. Dalkey, O. Helmer, An experimental application of the DELPHI method to the use of experts, Management Science, 9 (1963) 458-467.

[27] K.-T. Cho, Y.-M. Park, D.-H. Shin, J.-I. Lee, Technology forecasting survey on postharvest management using Delphi method, Korean Journal of Horticultural Science \& Technology, 22 (2004) 251-260.

[28] Y.C. Yun, H.J. Gi, H.K. Soung, A Delphi technology forecasting approach using a semi-Markov concept, Technol. Forecast. Soc. Chang., 40 (1991) 273-287.

[29] C. Hussler, P. Muller, P. Ronde, Is diversity in Delphi panelist groups useful? Evidence from a French forecasting exercise on the future of nuclear energy, Technol. Forecast. Soc. Chang., 78 (2011) 1642-1653.

[30] L.A. Bloem da Silveira Junior, E. Vasconcellos, L. Vasconcellos Guedes, L.F.A. Guedes, R.M. Costa, Technology roadmapping: A methodological proposition to refine Delphi results, Technol. Forecast. Soc. Chang., 126 (2018) 194-206.

[31] S. Di Zio, J.D. Castillo Rosas, L. Lamelza, Real Time Spatial Delphi: Fast convergence of experts' opinions on the territory, Technol. Forecast. Soc. Chang., 115 (2017) 143-154.

[32] R. Wakefield, T. Watson, A reappraisal of Delphi 2.0 for public relations research, Public Relations Review, 40 (2014) 577-584.

[33] T.U. Daim, G. Rueda, H. Martin, P. Gerdsri, Forecasting emerging technologies: Use of bibliometrics and patent analysis, Technol. Forecast. Soc. Chang., 73 (2006) 981-1012. 
[34] G. Rueda, D.F. Kocaoglu, Diffusion of emerging technologies: An innovative mixing approach, in: 2008 Portland International Conference on Management of Engineering \& Technology, 2008, pp. 672-697.

[35] G. Harell, T.U. Daim, Forecasting energy storage technologies, Foresight, 11 (2009) 74-85.

[36] S.W. Choi, Y.Y. You, K.S. Na, Forecasting promising technology using analysis of patent information: Focused on next generation mobile communications, Journal of Central South University, 21 (2014) 4303-4310.

[37] M.N. Kyebambe, G. Cheng, Y.Q. Huang, C.H. He, Z.Y. Zhang, Forecasting emerging technologies: A supervised learning approach through patent analysis, Technol. Forecast. Soc. Chang., 125 (2017) 236-244.

[38] S. Jun, S.S. Park, D.S. Jang, Technology forecasting using matrix map and patent clustering, Industrial Management \& Data Systems, 112 (2012) 786-807.

[39] G.J. Kim, S.S. Park, D.S. Jang, Technology Forecasting using Topic-Based Patent Analysis, Journal of Scientific \& Industrial Research, 74 (2015) 265-270.

[40] H.L. You, M.J. Li, K.W. Hipel, J. Jiang, B.F. Ge, H.T. Duan, Development trend forecasting for coherent light generator technology based on patent citation network analysis, Scientometrics, 111 (2017) 297-315.

[41] B. Yoon, Y. Park, Development of new technology forecasting algorithm: Hybrid approach for morphology analysis and conjoint analysis of patent information, IEEE Transactions on Engineering Management, 54 (2007) 588-599.

[42] Y. Huang, D.H. Zhu, Y. Qian, Y. Zhang, A.L. Porter, Y.Q. Liu, Y. Guo, A hybrid method to trace technology evolution pathways: a case study of 3D printing, Scientometrics, 111 (2017) 185204.

[43] K. Haegeman, E. Marinelli, F. Scapolo, A. Ricci, A. Sokolov, Quantitative and qualitative approaches in Future-oriented Technology Analysis (FTA): From combination to integration?, Technol. Forecast. Soc. Chang., 80 (2013) 386-397.

[44] A. Eerola, I. Miles, Methods and tools contributing to FTA: A knowledge-based perspective, Futures, 43 (2011) 265-278.

[45] K. Chen, S.H. Kung, Synthesis of qualitative and quantitative approaches to long-range forecasting, Technol. Forecast. Soc. Chang., 26 (1984) 255-266.

[46] X. Li, Y. Zhou, L. Xue, L. Huang, Integrating bibliometrics and roadmapping methods: A case of dye-sensitized solar cell technology-based industry in China, Technol. Forecast. Soc. Chang., 97 (2015) 205-222.

[47] Y.H. Chen, C.Y. Chen, S.C. Lee, Technology forecasting of new clean energy: The example of hydrogen energy and fuel cell, African Journal of Business Management, 4 (2010) 1372-1380.

[48] Y. Zhang, Y. Guo, X.F. Wang, D.H. Zhu, A.L. Porter, A hybrid visualisation model for technology roadmapping: bibliometrics, qualitative methodology and empirical study, Technol. Anal. Strateg. Manage., 25 (2013) 707-724.

[49] G. Intepe, E. Bozdag, T. Koc, The selection of technology forecasting method using a multicriteria interval-valued intuitionistic fuzzy group decision making approach, Computers \& Industrial Engineering, 65 (2013) 277-285.

[50] A.-C. Cheng, C.-J. Chen, C.-Y. Chen, A fuzzy multiple criteria comparison of technology forecasting methods for predicting the new materials development, Technol. Forecast. Soc. Chang., 75 (2008) 131-141.

[51] P.D. Wilmot, A comparison of the methods of technological forecasting, Industrial Marketing Management, 1 (1971) 95-102.

[52] Y. Huang, J. Schuehle, A.L. Porter, J. Youtie, A systematic method to create search strategies for emerging technologies based on the Web of Science: illustrated for 'Big Data', Scientometrics, 105 (2015) 2005-2022. 
[53] A.T. Roper, S.W. Cunningham, A.L. Porter, T.W. Mason, F.A. Rossini, J. Banks, Managing the present from the future, in: Forecasting and Management of Technology, John Wiley \& Sons, Inc., 2011, pp. 289-296.

[54] L. Gao, A.L. Porter, J. Wang, S. Fang, X. Zhang, T. Ma, W. Wang, L. Huang, Technology life cycle analysis method based on patent documents, Technol. Forecast. Soc. Chang., 80 (2013) 398407.

[55] Y.H. Chen, C.Y. Chen, S.C. Lee, Technology forecasting and patent strategy of hydrogen energy and fuel cell technologies, International Journal of Hydrogen Energy, 36 (2011) 6957-6969.

[56] Y. Guo, T.T. Ma, A.L. Porter, L. Huang, Text mining of information resources to inform Forecasting Innovation Pathways, Technol. Anal. Strateg. Manage., 24 (2012) 843-861.

[57] Nanosys, Who we are, in, 2018.

[58] I. Hod, V. González-Pedro, Z. Tachan, F. Fabregat-Santiago, I. Mora-Seró, J. Bisquert, A. Zaban, Dye versus Quantum Dots in Sensitized Solar Cells: Participation of Quantum Dot Absorber in the Recombination Process, The Journal of Physical Chemistry Letters, 2 (2011) 3032-3035.

[59] S. Kirsner, Why did solar cell company Konarka fail?, in, 2012.

[60] L. Huang, Y. Guo, A.L. Porter, J. Youtie, D.K.R. Robinson, Visualising potential innovation pathways in a workshop setting: the case of nano-enabled biosensors, Technol. Anal. Strateg. Manage., 24 (2012) 527-542.

[61] N.C. Newman, A.L. Porter, D. Newman, C.C. Trumbach, S.D. Bolan, Comparing methods to extract technical content for technological intelligence, J. Eng. Technol. Manage., 32 (2014) 97-109.

[62] Y. Zhang, A.L. Porter, Z.Y. Hu, Y. Guo, N.C. Newman, "Term clumping" for technical intelligence: A case study on dye-sensitized solar cells, Technol. Forecast. Soc. Chang., 85 (2014) 26-39.

[63] H. Hoppe, N.S. Sariciftci, Organic solar cells: An overview, Journal of Materials Research, 19 (2004) 1924-1945. 